\title{
REFORMULATING A SMART HOME SYSTEM FOR THE INDIAN CONTEXT: DIU ISLAND
}

\author{
DARPAN TRIBOAN ${ }^{1} \&$ ANISHA MEGGI ${ }^{2}$ \\ ${ }^{1}$ Context, Intelligence and Interaction Research Group, De Montfort University, UK. \\ ${ }^{2}$ Leicester School of Architecture, De Montfort University, UK.
}

\begin{abstract}
In a fast urbanizing world, the Smart City concept driven by leading technologies can be a saviour to the many urban, environmental and economic issues among other problems being faced by governments and citizens. The smart city concept is discussed in conjunction with long explored urban and architectural theories of utopia and ideal city design. Further expanding the conversation on the role of the home as a tool by which to live life, which has been understood as the current concept of Smart Homes (SH) and Ambient Assistive Living (AAL) systems. This paper focuses on a recently announced Smart city in India, Diu Island, which is the primary case study in the paper. Within the context of Diu Island, the issues faced by the elderly native population are investigated to propose a smart home living system that can help improve the quality of their daily lives. A hybrid approach is proposed that leverages edge and cloud computing paradigms to become self-powering, energy-efficient and reduces delays in aiding the elderly.
\end{abstract}

Keywords: Ambient Assisted Living, Diu Island, Smart City Mission of India, socio-cultural aware, Smart Homes, urbanisation.

\section{INTRODUCTION}

Smart cities are 21 st century technological utopias. When such utopian concepts are applied and practised by economically developing and emerging countries, it creates a complex contextual environment of aspirations and realities, converging histories and socio-cultural dynamics, [1]. In India, as urbanisation changes family structures and lifestyles, a society deeply rooted in joint family dynamics is becoming fragmented and leaving the elderly at risk of being isolated, neglected within the city. The case study in this paper investigates a recently announced Smart city, Diu Island, where historical, political aspects mean there is high migration of the native population, leaving behind the elderly in many cases. Within this environment of change, the elderly native population on the island face many city-level but first and foremost daily household challenges, which this paper will focus on.

To understand the Smart City concept wholly, the literature review in this paper delves into the architectural and urban theories on ideal cities that capture ideas from the Renaissance ideal cities of the 15-16th centuries. By gaining an understanding of the historical and more contemporary ideologies of managing, organising and designing a city the future of smart cities can also be better evaluated. The smart city concept in the early 20th century can be compared to the technologically based utopian visions of Le Corbusier [2]. His critically debated quote 'house is a machine for living' becomes a pivotal point allowing the research to take on the Smart Home system and specifically the Ambient Assistive Living (AAL) approach to be developed for contextually complex environments.

This paper aims to investigate and re-formulate a smart home system for a culturally complex context within Diu Island. The main objectives being; (1) to comprehensively document, critically analyse and evaluate literature in the smart home, smart city environment in India, (2) to select and investigate a problem context that requires smart home interventions, this will be the context of Diu Island specifically the migrant village of Fudam, (3) to recognise 
and evaluate methods of smart home interventions for the problem context, (4) to reformulate a method of smart home intervention for the problem recognised in the case study, (5) to evaluate the impending potential and scope of the method applied and propose future avenues of research.

\section{RESEARCH METHODOLOGY}

This paper utilises a literature review and qualitative primary case study to understand a problem context, which determines the research objectives. The research is constructed in the following stages; awareness, suggestion, development, evaluation, and conclusion, [3].

The literature review covers (1) urbanisation in South Asia, concept of 'Smart Cities', (2) contextualisation of the environment surrounding old age homes and elderly living alone in their homes in India, and (3) various smart home systems available, allow for the recognition and critical comparison and analysis of smart home systems.

The qualitative primary case study of Diu Island will allow for an in-depth contextual investigation of a specific case where contextual complexities will be understood from a wider variety of perspectives. The context will be studied for the recognition of a specific problem area that exists and a smart home system to be applied and evaluated. This will allow for the proposal of a hybrid smart home system that is appropriate for the problems recognised in the case study to apply, test and evaluate the smart home system method.

The primary case study is a part of research conducted in [4], [5] whilst understanding the derelict and decaying built environment, the issues of the elderly inhabitants who had chosen not to leave their homes was recognised. The researcher's site visits and observations of the elderly residents and their lives become an integral part of composing the problem context for this paper. The criteria for analysing this case study are the; political, economic, social, technological, environment and architectural aspects that will be analysed for opportunities and restrictions. The smart home system that is modified and proposed for the problem context recognised in the primary case study will be discussed, evaluated and further research will be proposed.

\section{LITERATURE REVIEW}

\subsection{Smart Cities, Utopia and the future of cities in India}

There is no common meaning of a 'smart city' is however all meanings converge on being 'technologically based', [6]. The World Bank suggests two meanings; where there are sensors everywhere, collecting real-time data from interconnected devices, and a city that cultivates better relationships between citizens and the government. It was IBM who coined the 'smart city' phrase in 2008 and is the market leader in smart city suppliers, [7]. There has been some concern due to the roles private corporations are playing in defining what a smart city is, where the smart city is becoming more of a corporate smart city. A case study on the smart city of Genoa exemplifies how the smart city concept acts as a promoter of interests for the business elites diverting the attention away from urgent problems such as urbanization, [6].

In the Smart Cities Mission for India, the government body recognises there is no set meaning for the term smart city hence, smart city would have a different connotation in India than it has in Europe, [7]. An example of the failure of a smart city whose model was implanted straight from Europe into India is Lavasa, [8]. The overall objective of smart growth anywhere would be for sustainable, economic and social progress to occur, [9]. 
Smart City initiatives are said to be agreed between the government and private companies, which questions the marginalisation of vulnerable populations. It has been reported that the smart city initiatives in India have meant forced acquisition of land and relocation of street vendors and middle class communities from the centre of cities to other areas, [7]. Some specific recommendations in smart city initiatives is citizen participation that should be integral to all parts of decision making, [7]. Within smart city initiatives, the idea that one size fits all is most problematic as each city being designated the smart city title has its own identity, cultural values and ways of life which need to be sustained in its process to becoming 'smarter'. In addition, this can only be done when the citizens who are key components of the city's identity are part of the different levels of decision making and implementing and testing.

Borja argues that, technology does not always play in the favour of citizens, within the smart city where technology is one of the basic principles. In 2013 Greenfield in, 'Against the Smart Cities', states that the concept of the intelligent, smart city has been completely derived by private companies. The smart city is stated to be an ideological technological utopia for the future of cities, [9]. More specifically, concrete utopia distinguished by E. Bloch, 1995,refers to a project connected to reality allowing citizens to progress towards historical and social transformation.

Utopian thinking has played a critical role in the discipline of city planning. Utopians, urban planners and urban theorists have been testing and using the urban environment as a laboratory for new ways of living and organising the city; Fig. 1. Mario Chiattone in Modern Metropolis 1914, shows a utopian city that is vertical with technological challenges. In 1964, Archigram's Plug-in-Play city is a dream of the mutant city, always growing and never equal to itself, adopting to changes and stimulating creativity. It has also been noted that there are certain references in the ideal city of Campanella, 1602, which is a super positioning of six spheres, like that of the 21 st century Smart city today where space dematerialises in to and as networks. Similarly, the Garden City ideology by Ebenezer Howard also constructs a radial city with six spheres. In this manner the Smart City could be a model, a system or ideology that deals with solutions, improvement and evolution of the contemporary city, [9].

The role of innovation has always brought about profound change, for example the Industrial Revolution, the advent of electricity, the invention of the automobile and use of reinforced concrete within construction, [9]. It is at this point that mentioning Le Corbusier and his proposal of the Ville Radieuse is most apt. The city is proposed as an architectural ideology that is closely aligned to the financial and economic conditions of

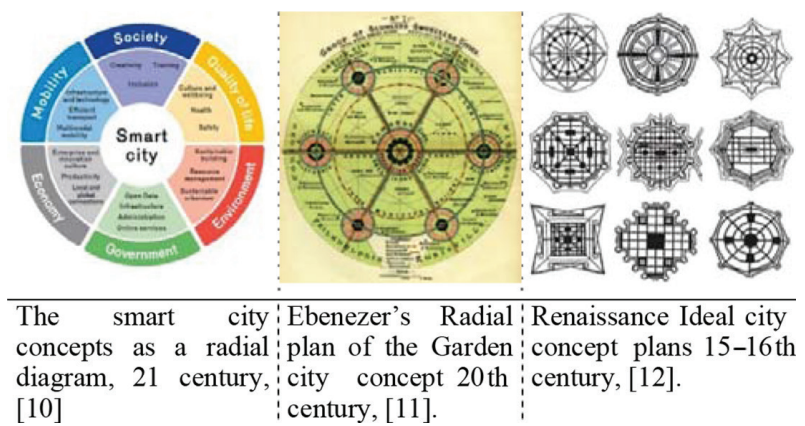

Figure 1: The concept of Ideal Cities from 15 th century to 21 st century. 
a capital and designed with wide boulevards accommodating for multi lane traffic in both directions with a high density for the residential blocks. Though his radical technical ideas are said to be tamely adapted in to the Ville Radieuse, the city is a proposal to solve the housing crisis within quickly urbanising cities of the 21st century, [2]. Alongside utopias where the latest technological advances are accommodated for, in Le Corbuiser's case, that being the automobile, there are urban theorists who believe strongly in a city designed for people. The likes of Jane Jacobs and Jan Gehl, who advocate a city that is constructed for people as per their needs and a city which in turn shapes the people. In addition, Gehl deals with the same issues as Le Corbuiser of a growing population and economic issues but also environmental issues with focus on sustainability and citizens health. Gehl speaks of the human scale within cities, the 'disgraceful' city spaces all people face where traffic, congestion and pollution have become a norm, cars and carparks have taken over a space that might otherwise be a public park for people to meet and greet within. Instead of using the car, it would be sustainable for citizens health with bicycle lanes introduced, [13].

The smart city in this manner seems like a technological ideology predominantly with many of the aspects that many of the urban theorists and architects have been considering and dealing with for a long time. In this paper, the emphasis is on smart cities that are about people, focused on the inhabitants for their benefit, a city for people, by the people. India being one of the largest democracies in the world with 1.36 billion as a population [14], this paper aims to investigate bottom up approaches, as a method to empower and bring change and benefit to the individuals of a large, vast and diverse population by valuing what is already there within the context of each city. Instead of proposing ideas based on predictions of how inhabitants might or should live, to understand the existing values and shortfalls of a context and to design/ propose as per those requirements, [15].

\subsection{Smart Homes in India}

The Indian family home has long been known for the joint family ensemble. However, this is fast changing with urbanisation playing a key role in the way family life is evolving. The service class in urban India in the last decade sees a rise in nuclear living. Nuclear living in India is more to do with not living together due to working or studying in another city, it can be described as non-joint living, [16]. An increase in life expectancy has also meant that the elderly population will grow from 91.6 million in 2010 , to 157.8 million by 2025 . This means that the elderly, in quickly urbanising areas of the country, are vulnerable to living alone and needing care on different levels. It is therefore stated that as the elderly population increases and urbanisation continues life style changes and social challenges faced by the elderly need to be investigated to improve the quality of life that can be led independently, [17].

One such socio-cultural issue within the aging population in India is to continue living at home rather than go to a care home, which is considered shameful. Culturally members of the joint family and even now smaller nuclear families are expected to look after terminally ill elderly family members who might be living away from them. This creates an issue as lifestyles become busier, thereby dependant elderly family members are isolated and neglected in their own homes leading to a low quality of life. So how can homes be developed to allow the elderly person to continue living a life of dignity, and self-care for as long as possible? One ideology that can be useful to consider is that of Le Corbusier; 'the house is a machine for living'. Whilst the idea of architecture as a machine has been criticized for standardising 
human needs within different contextual issues, standardisation was used as a method to create human wellbeing, [18]. Corbusier states his famous quote in the sense that, "baths, sun hot-water, cold water, warmth at will, conservation of food, hygiene... an arm chair is a tool for sitting on...', so in short the house is considered to be an efficient tool to help support the delivery of the necessities of life, [19]. Within the smart city paradigm, the 'smart home' can be considered similar in its essence to Corbusier's ideology.

A 'smart home' is a term used for the advanced automated systems that supports inhabitant in daily activities to improve the quality-of-life. A smart home ( $\mathrm{SH}$ ) system is an environment equipped with emerging Internet-of-Things (IoT) technologies. IoT technologies are essentially sensing devices and actuators that are attached to everyday objects in a given environment/space. IoT devices are interconnected and accessible over the internet. Therefore, creating capabilities such as monitoring activities of daily living (ADL), automating and adapting to inhabitant's context to provide just-in-time assistance.

Recent literature has investigated low cost $\mathrm{SH}$ solutions such as microcontroller-based that are flexible and scalable [20], and remote access to SH devices [21]. Research in [22] has proposed monitoring and controlling $\mathrm{SH}$ environments. It proposes the microcontroller and MQTT cloud platform-based approach for SH monitoring; control (appliances/lighting), detect (intrusion/smoke/gas) and alerting (danger/anomalies). Although, microcontroller-based solutions are flexible, reduce cost and have a higher scalability, there are number of challenges with this approach. One of the key limitations of this approach is that it requires expert knowledge to setup the system and when adding new sensors. The setup process involves three main steps; wiring sensors to microcontroller, programming microcontroller and software system collecting data. Hence, to add new sensors, the three-step setup process need to be repeated. There have been some efforts being made to ease the three-steps setup process for microcontroller-based solutions such as 'over-the-air' programming/firmware upgrade. However, it remains a challenge to create 'plug-and-play' solutions.

Commercial SH kits are now emerging in India and around the world with proprietary and open source components. These kits contain a variety of devices for vision and ambient sensing (i.e. temperature, lighting, switches, motion, and door/window) technologies. For instance, Samsung SmartThings, Insteon and Oakter kit are some of the popular kits available over Amazon India. Other more specialist security kit such as Arlo, iSmartAlaram and SimpliSafe are also available with advance features such as intrusion detection and monitoring. For instance, smart doorbell and smart monitoring cameras that combine camera, motion and sound detection for smart alerting and notification technologies. Most of the kits such as SmartThings, come with a smart hub that support wired and wireless sensors with multiple communication protocol such as ZigBee, Z-Wave, and WiFi. These hubs enable 'plug-andplay' features to add new wireless sensors from different manufacturers effortlessly. Despite the ease of configuring sensors in desired location, the wireless sensors have limited battery life and require frequent replacement. Other devices connected to main power lines are also available that can control lighting and electrical appliances such as Maxico and WeMo switches and plugs. With a vast diversity in sensing technologies and manufacturers, the complexity of interacting with all the devices with individual mobile applications is one key technical challenge. New waves of technology are now emerging such as Amazon Alexa and Google Home that can interact with smart sensors within the SH environment with voice-commands. These speech-based Human-computer Interaction (HCI) capabilities are advantageous for non-technical expert users. However, in the context of India, English is not the first language and detecting popular spoken languages and dialects such as Hindi, Urdu, Bengali, 
Marathi and Gujarati remain a research challenge for voice recognition and speech-based technology.

\subsection{Ambient Assisted Living (AAL) Systems}

Smart home technologies are being utilised to create AAL around the world to support the aging population and people with disabilities [23]. India is advancing to invest in AAL systems with fast urbanisation, nuclear living, and elderly population living alone. AAL encourages independent living by supporting in carrying out Activities of Daily Living (ADL) in their own home. Human Activity Recognition (HAR) is a key part of AAL systems to allow accurate and timely assistance to the inhabitant or carers. The detection of anomalies (i.e. fall), recognising ADLs and changes in daily routines are some of the well-studied research areas in the realm of AAL systems. However, a number of challenges such as multi-occupancy AR, hybrid activity learning and ubiquitous SH monitoring approaches are being investigated by research communities [24]. HAR approaches pave the way for applications in other domains such as healthcare, security, surveillance, smart cities, smart grids, and e-commerce [25].

\section{PRIMARY CASE STUDY}

\subsection{Diu: A Smart City}

Diu Island located on the south west coast, off Gujarat, India, is a former Portuguese colony under the Indian government since 1961. Beyond the town walls, lie several villages, Fudam being one, [26]; see Fig. 2. It was reported that nearly $85 \%$ of the native local population has migrated to Europe, [27], however many elderly have stayed back in order to continue living in ancestral properties and land.

The elderly lives in their own homes, alone, and are visited by family on a yearly basis. This situation has created many issues from robbery and home safety, to untreated and the onset of chronic illnesses. Recently, CCTV and cameras are being installed by some migrant family members to see their properties and elderly parents in real-time.

\subsection{The Migrants Home Village - Fudam}

Fudam village is the ancestral village of one of the authors of this paper. It like many other villages on Diu Island is home to the natives who have migrated to Europe. During a series of research trips to Fudam the researcher noticed a serious lack of infrastructure on the island and within individual homes to support the needs of elderly residents like her grandmother. There is an issue with safety within the home and vulnerability. Elderly inhabitants are hard of hearing but do not wear hearing aids due to socio-cultural embarrassment. Grandma's home is relatively small, a one story detached structure set on a large piece of land that allows for both a front and back garden. The toilet is set at the back of the garden. A fading and weakening memory along with hearing issues means the home environment can become dangerous. Additionally, issues such as; guidance over a hob that is left on by mistake, care and assistance after a fall in the home or when unwell are prevalent. Risks of dangerous animals entering the homes, like snakes and monitor lizards are also high due to gardens and neighbouring fields. 


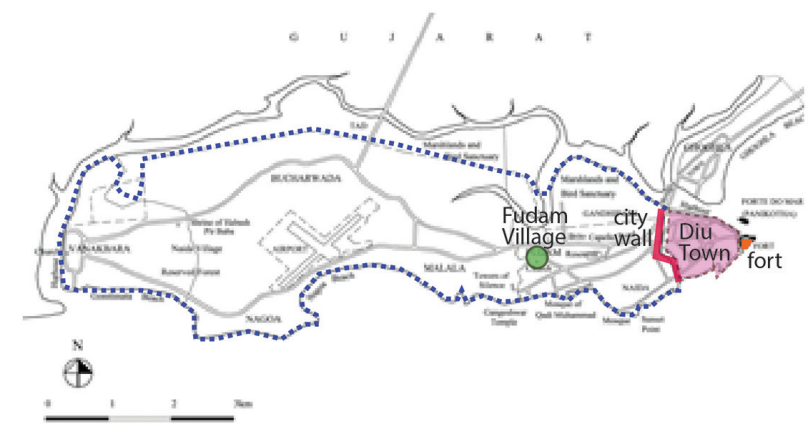

Figure 2: Map of Diu Island showing Fort, Town Wall and Fudam, [26].

\subsection{Analysis of Diu for Smart Home System Proposal}

Table 1: Table showing opportunities, restrictions and requirements for the SH system.

\begin{abstract}
Social-cultural - Opportunities $(\boldsymbol{O})$; SH systems can improve the socio-cultural dynamics, giving elderly a better quality of life as they can feel more in control of security of their homes. Restriction $(\boldsymbol{R})$; Awareness off and demand for the technology is not there as the elderly don't usually know the latest technology that can help them. The latest technology is not always received in the positive manner as it can be alien and hard to relate to such technologies but also use. Requirement $(\boldsymbol{R q})$; visual elements of the system must be recognised, so the users can get accustomed to the technology quickly or not even realise new technological advances have been integrated in to older devices.
\end{abstract}

Political - $\boldsymbol{O}$; Smart cities can enable elderly people to live a quality life within their own. $\boldsymbol{R}$; Budget for private home owners is not available from the council. $\boldsymbol{R} \boldsymbol{q}$; No initial financial help, the system needs to be cost effective and conceptually still in this paper but initiate the idea of giving more power to the individual rather than corporates.

Technology - $\boldsymbol{O}$; A different context within this case study allow for innovative solutions to the existing technology in smart home systems. $R$; Electricity cuts due to maintenance. The technology has to be user friendly and relatable, rather than seen as a new alien technology that the users feels they cannot use. $\boldsymbol{R} \boldsymbol{q}$; batteries within sensors will need to be replaced 6-12 months, the system needs to have minimal maintenance.

\section{Environmental - $\boldsymbol{O}$; The tropical climate and the island's geographical location allows for the use of wind or solar power. $\boldsymbol{R}$; Temperatures and humidity levels are high during dif- ferent parts of the year and so need to be taken in to consideration for sensors and other parts of the smart home system. $\boldsymbol{R} \boldsymbol{q}$; the system should try to utilise wind and solar power, in addition wild animals need to be recognised within the system which can be a problem with a large area of outdoor space to cover.}

Economical/Financial - $\boldsymbol{O}$; Many private companies are already investing in SH devices in India. $\boldsymbol{R}$; Large cost for elderly to afford though migrant family members could afford the $\mathrm{SH}$ systems. Rq; Cost effectiveness.

Architectural - $\boldsymbol{O} / \boldsymbol{R}$; The houses are simple in both layout and interior furnishings which allows for the technology to be set up easily. $\boldsymbol{R} \boldsymbol{q}$; The smart home system needs to be as non-intrusive as possible so that the lived experience of their home is conserved for the elderly person. 


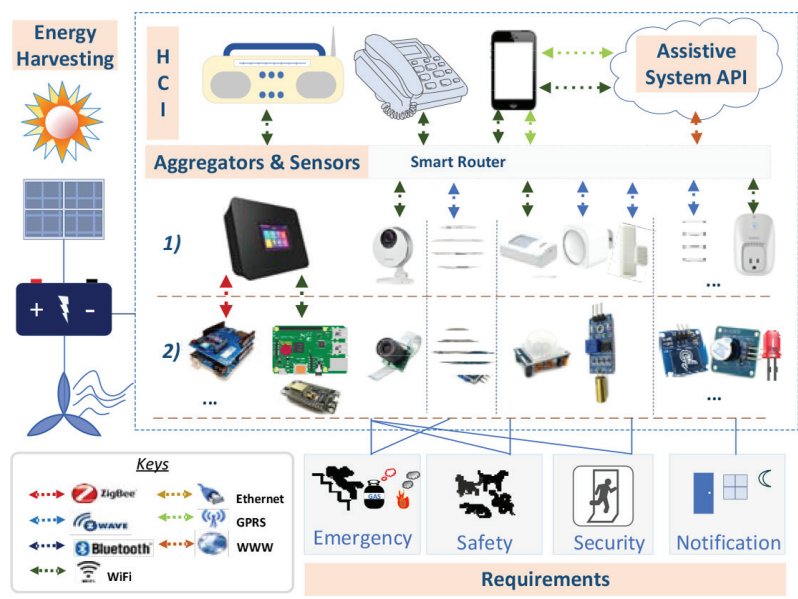

Figure 3: A hybrid edge and cloud computing system architecture of the assistive living system in relation to the socio-cultural primary case study requirements.

\section{SOCIO-CULTURAL BASED AMBIENT ASSISTED LIVING}

A conceptual view of the proposed AAL and SH technologies approach is depicted in Fig. 3. The approach takes requirements identified in section 4.3 to develop a hybrid computing architecture that is resilient to the power cuts, work with low internet speed and data allowance, cost-effective, and easy to use. To ensure critical components of the SH environment are functional in the event of power cuts, solar and wind energies will be utilised and stored in a battery. An energy monitoring system based on the microcontroller will monitor energy status from the main power grid and switch to battery power energy automatically, [28]. The assistance requirements from the case study can be categorised as emergency, safety, security and notification services. For this, activity recognition with suitable sensing and notification methods for the elderly are highlighted in the following sections.

\subsection{Activity Recognition and Pattern Learning}

A hybrid activity recognition and pattern learning [29] algorithms are required to adapt to the resident's lifestyle. Although, the proposal for new algorithms are out of the scope of the paper, this paper proposes to delegate these tasks of activity recognition and learning by leveraging the cloud computing and edge computing paradigm. Cloud computing is a centralised approach, which offloads all sensor data collected from the smart home/city environment and the analytics tasks to remote servers. The cloud computing approach is typically used by current AAL systems to store large volumes of sensor data and perform hardware intensive tasks more efficiently. However, the key limitations of cloud computing are that it requires high internet bandwidth to communicate a large quantity of sensor data to the server, which creates a delay in response time, and requires expensive server resources. Therefore, the edge computing paradigm is introduced to create a decentralised approach to delegate some of the computational tasks to aggregators or devices closer to the sensors. Currently, off-the-shelf sensing platforms mainly adapt the cloud computing approach. Hence, the use of bespoke sensing devices will enable the edge computing setup to reduce internet data consumption, increase reliability and continue working even in the event of power outages in the village with the help of the dynamic energy management system. 


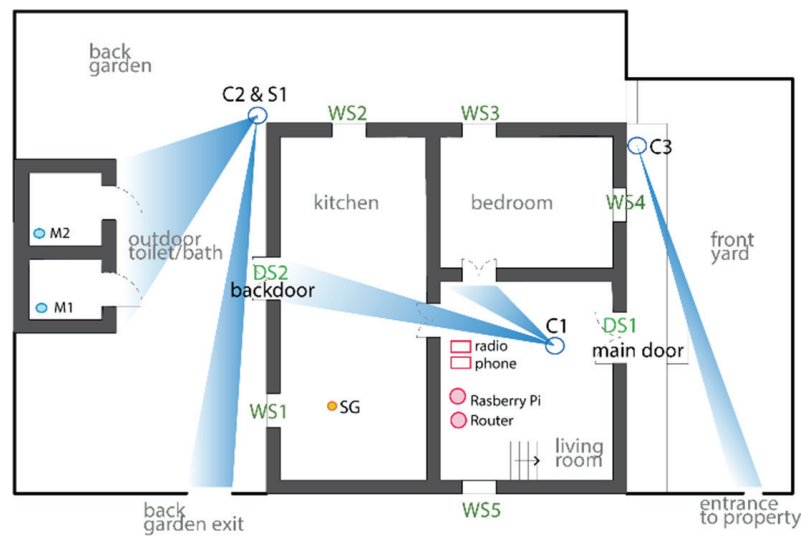

Figure 4: Distribution of smart home environment with sensors and actuators for ambient assisted living system.

\subsection{Intelligent Smart Home Environment}

The smart home environment will contain a combination of vision and ambient sensing approaches as illustrated in Fig. 4. The main purpose of the vision-based sensing approach is to detect animals, falls, and intruders. Three cameras $\left(\mathrm{C}_{\mathrm{m}}\right)$ are strategically placed by the door $\left(\mathrm{DS}_{\mathrm{n}}\right)$ and windows $\left(\mathrm{WS}_{\mathrm{o}}\right.$ ) without compromising privacy of the resident as illustrated by the ground floor plan in Fig. 4. $\mathrm{C}_{1}$ is positioned inside the house to allow viewing of both main doors. $\mathrm{C}_{2}$ and $\mathrm{C}_{3}$ allow the coverage of the entrances in to the gardens. $\mathrm{C}_{2}$ has a speaker $\left(\mathrm{S}_{1}\right)$, which allows the doorbell to be heard whilst in the garden. The first floor has another four windows and two doors which would be deployed in the same manner. A low-cost bespoke raspberry Pi and camera-based video processing [30] approach is proposed to detect animals and falls. The live video from a standard camera will allow the raspberry Pi to detect objects and alert the resident. Off-the-shelf cameras are also available at a higher cost and come with a number of advanced features typically used for security and intrusion detection, i.e. motion and sound based recording/alerting, and night vision.

An ambient sensing method will enable personal space to be monitored unobtrusively. For instance, magnetic sensors can detect if the door and windows are open/close and passive infrared (PIR) sensors to detect movement in a given room or garden toilet/bathroom. A low-cost solution will be to deploy with miniature microcontrollers that are wireless and consume low-energy such as ESP8266 12E or Witty Cloud with different types of ambient sensors such as reed switch, smoke/gas $\left(\mathrm{SG}_{\mathrm{p}}\right)$, temperature $\left(\mathrm{T}_{\mathrm{q}}\right)$, motion $\left(\mathrm{M}_{\mathrm{r}}\right)$, sound $\left(\mathrm{S}_{\mathrm{s}}\right)$, and touch $\left(\mathrm{TO}_{\mathrm{t}}\right)$. A collection of slave microcontrollers integrated in the telephone and radio are interconnected with the main hub located in the living room to process the sensor data and respond to events automatically. The hub can also selectively publish important data to the cloud web service for behaviour pattern detection overtime and other complex analytics on powerful servers. For this, an assistive system web service will be made accessible over the cloud with application programming interface (API).

\subsection{Human-computer Interaction}

$\mathrm{HCI}$ is a critical factor to consider for engaging elderly with age related problems, limited literacy and no technical skills to use the SH systems being designed. New voice-based speakers such as Amazon Alexa and Google Home technology are becoming increasing 
popular to control the smart environment and notify residents. However, these smart speakers mainly function on strong Wi-Fi connectivity and do not support native languages. Although, Google Home only recently launched the support for Hindi language for Google Home, more efforts are still needed. These emerging smart devices (i.e. speaker designs, phones, TVs, watches) are not only challenging to operate for elderly with fading memory but they cannot relate to these objects as a friendly tool that they were so used to in past. Therefore, objects such as radio and telephone designs integrated with advance features are proposed to be more relatable objects in the elderly's home environment. An elderly with hearing problems may also feel anxious of being prompted unpredictably without warning, hence, a devotional sound is proposed to be used to get their attention first and then provide any information needed. Therefore, the radio will have storage space for devotional or favourite songs for leisure and notification purposes, and wireless connectivity with the main hub. The landline telephone will be optimised for speed dialling a set of contacts and emergency services and have additional buttons with LEDs flashing to dial a pre-defined contact number. For this, both radio and telephone will be customised using the raspberry pi.

\section{DISCUSSION \& EVALUATION}

India's 100 smart cities mission is a long way to serving private homeowners directly to improve quality of life and independent living in their own home instead of going to care homes at old age. There are little to no schemes available from the government or local councils for the elderly to invest in SH systems. The overall costs of installing AAL systems with advanced smart home devices are still high and unfeasible for the elderly in some parts of India. In general, the benefits of these technological tools such as improved safety, security and support in ADLs are still not well unknown or conveyed to the elderly. Consequently, greater awareness of such technology will increase their ability to embrace them.

New waves of assistive technology are still in their infancy and companies must tailor their products so that they are relatable and enhance existing objects in the home environment to specific stakeholders such as the elderly. Therefore, this paper revisits old relatable devices such as radio and wired telephone for the elderly to feel less alienated with the new technology and age-related challenges such as weakening cognitive ability and fading memory. There are several technical and practical challenges in developing a mature, one AAL solution. For instance, developing sensing devices that can be self-discoverable, self-powering [31] and unobtrusively integrated into our environment or worn body with the likes of sound [32], and smart clothing/textile [33] technologies.

\section{CONCLUSION AND FUTURE WORK}

In this paper, it can be understood that using existing technologies within the homes of the elderly along with customising and connecting familiar technologies from the elderly person's experience a smart home system can be designed around specific socio-cultural and environmentally inherent issues. Many issues exist within the proposal made in this paper. The social, cultural and wider critical thoughts regarding the conceptual proposal in this paper are; (1) currently, grandma in the case study is used to having two cameras in the house already, one in the living room and one in the garden. Cameras are considered intrusive and unethical at times, depending on where they are installed.

The proposal in this paper uses existing cameras and grandma's familiarity with them. But in other contextual situations, cameras might not be utilised as liberally as done in this case. (2) In different contexts, different current technologies like smart phones and smart TV can 
be more appropriate. Currently, grandma has a standard TV, which she only watches an hour a day and a smart phone which she doesn't know how to use. However, the use of smart phones and smart TV's by the other elderly in other regions might be higher and can be integrated in the SH system. (3) Also, in some parts of India, villages are still struggling with electricity, water and home sanitation which becomes an important factor in the overall quality of life for the elderly, which could pose more interesting problem contexts to deal with.

Methodologically, future research should take a larger sample of case studies/scenarios within a particular city, or urban environment to understand the diversity of the needs of the elderly living within the city/area. Moreover, a prototype will be developed in future work, based on the proposed approaches.

\section{REFERENCES}

[1] Ismail, N., Smart Cities in India: Embracing the Opportunity of Urbanisation, 2018.

[2] Teige, K. \& Dluhosch, E., The minimum dwelling [Internet]. Chicago; 2002. (Mit Press). available at https://books.google.co.uk/books?id=3Q4TYPRPKpUC

[3] Hinkelmann, K. \& Witschel, H.F., How to Choose a Research Methodology, Univeristy Appl Sci Northwest Switzerland, Sch Bus. 2009.

[4] Meggi, A., Representing the colony: Documenting the other perspective. In Historical Perspectives Global Communities Conference,. Kelvin Hall, Glasgow, 8-9 June 2018.

[5] Meggi, A., Towards a digital heritage: Evaluating methods of heritage interpretation, diu town-a case study. International Journal of Heritage Architecture: Studies, Repairs and Maintence [Internet], 2(3), pp. 406-416, 2017. available from http://www. witpress.com/doi/journals/HA-V2-N3-406-416

[6] Grossi, G. \& Pianezzi, D., Smart cities: Utopia or neoliberal ideology? Cities, 69, pp. 79-85, 2017. https://doi.org/10.1016/j.cities.2017.07.012

[7] International P. Smart cities: Utopian Vision, Dystopian Reality. 2017;(October).

[8] Anto, A. \& Dhwani P., How the unfinished city of Lavasa became a nightmare for Indian banks | Business Standard News [Internet]. available at https://www.business-standard. com/article/current-affairs/how-the-unfinished-city-of-lavasa-became-a-nightmare-forindian-banks-118061900095_1.html, 2018 (accessed 7 February 2019).

[9] Mata, A.M., Is Smart City an Utopia? Lessons Learned and Final Reflections, July 2018.

[10] Brussels Smart city [Internet]. available at https://smartcity.brussels/the-project-definition 2019 (accessed 7 Febrauary 2019).

[11] Grand Reductions: 10 Diagrams that Changed City Planning [Internet]. Urbanist Article. available at https://www.spur.org/publications/urbanist-article/2012-11-09/ grand-reductions-10-diagrams-changed-city-planning, 2012.

[12] Grand Reductions: 10 Diagrams that Changed City Planning. Urbanist Article. 2012.

[13] Gehl, J. \& Rogers, R., Cities for People [Internet]. Island Press, available at https:// books.google.co.uk/books?id=lBNJoNILqQcC, 2013.

[14] India Population [Internet]. available at http://www.indiapopulation2019.in/ 2019 (accessed 7 February 2019)

[15] Lee, T. \& Jane, J., Bottom-Up Thinker [Internet]. available at http://timothyblee. com/2010/07/13/jane-jacobs-bottom-up-thinker/, 2013 (accessed 7 Febraury 2019).

[16] Patel, T., The Family in India: Structure and Practice [Internet]. Sage Publications; (Themes in Indian sociology). available at: https://books.google.co.uk/books?id=K1_Ve_GKOIC, 2005. 
[17] B Mane A. Ageing in India: Some Social Challenges to Elderly Care. J Gerontol Geriatr Res [Internet]; available at http://www.omicsgroup.org/journals/ageing-in-indiasome-social-challenges-to-elderly-care-2167-7182-1000e136.php?aid=69369, 2016.

[18] Atmodiwirjo, P. \& Yatmo, Y.A., Architecture as machine: Towards an architectural system for human well-being. LC2015-Le Corbusier, 50 Years Later, pp. 1-10, 2015.

[19] Morse, G., What is a Machine for living in? [Internet]. available at https://placeexploration.com/2015/10/28/a-house-is-a-machine-for-living-in/, 2015 (accessed 7 February 2019).

[20] Nath, P. \& Pati, U.C., Low-cost android app based voice operated room automation system. In 2018 3rd International Conference for Convergence in Technology (I2CT), IEEE, pp. 1-4, 2018 ..

[21] Shailendra, E. \& Bhatia, P.K., Analyzing Home Automation and Networking Technologies. IEEE Potentials [Internet], 37(1), pp. 27-33, 2018. available at http://ieeexplore. ieee.org/document/8253757/

[22] Malche, T. \& Maheshwary, P., Internet of Things (IoT) for building Smart Home System. In IoT in Social, Mobile, Analytics and Cloud, pp. 65-70, 2017.

[23] Banks, B.J., The 'age' of opportunity. IEEE Pulse, 8(2), pp. 12-5, 2017.

[24] Ihianle, I.K, Naeem, U., Syed, I. \& Tawil, A.R., A hybrid approach to recognising activities of daily living from object use in the home environment. Informatics [Internet], 5(1), pp. 1-25, 2018, available at http://www.mdpi.com/2227-9709/5/1/6

[25] Aouedi, O., Anis, M., Tobji, B. \& Abraham, A., Internet of things and ambient intelligence for mobile health monitoring : A review of a decade of research. Int J Comput Inf Syst Ind Manag Appl., 10, pp. 261-270, 2018.

[26] Shokoohy, M. \& Shokoohy, N.H., The island of diu, its architecture and historic remains. South Asian Stud [Internet], 26(2), pp. 161-191, 2010. available from: http:// dx.doi.org/10.1080/02666030.2010.514743

[27] Rahman, A.P., With the island's old-timers moving to Europe, Diu's 400-year-old Portuguese influence is fading [Internet]. The Hindu. available at https://www.thehindu. $\mathrm{com} /$ society/with-the-islands-old-timers-moving-to-europe-dius-400-year-old-portuguese-influence-is-fading/article23528249.ece, 2018 (cited 2 February 2019).

[28] Srivastava, P., Bajaj, M. \& Rana, A.S., IOT based controlling of hybrid energy system using ESP8266. 2018 IEEMA Eng Infin Conf eTechNxT 2018, pp. 1-5, 2018.

[29] Chen, L., Nugent, C. \& Okeyo, G., An ontology-based hybrid approach to activity modeling for smart homes. IEEE Trans Human-Machine Syst, 44(1), pp. 92-105, 2014.

[30] De Miguel, K., Brunete, A., Hernando, M. \& Gambao, E., Home camera-based fall detection system for the elderly. Sensors (Switzerland), 17(12), 2017.

[31] Lin, Z., Yang, J., Li, X., Wu, Y., Wei, W., Liu, J., Chen, J., \& Yang, J., Large-scale and washable smart textiles based on triboelectric nanogenerator arrays for self-powered sleeping monitoring. Adv Funct Mater [Internet], 28(1), p. 1704112, 2018. available at https://onlinelibrary.wiley.com/doi/abs/10.1002/adfm.201704112

[32] Giannakopoulos, T. \& Konstantopoulos, S., Daily activity recognition based on meta-classification of low-level audio events. ICT4AWE 2017 - Proc 3rd Int Conf Inf Commun Technol Ageing Well e-Health. 2017.

[33] Wen, Z., Yeh, M.H., Guo, H., Wang, J., Zi, Y., Xu, W., Deng, J., Zhu, L., Wang, X., Hu, C., Zhu, L., Sun, X., \& Wang, Z. L., Self-powered textile for wearable electronics by hybridizing fiber-shaped nanogenerators, solar cells, and supercapacitors. Science Advances [Internet], 2(10), 2016, available at http://advances.sciencemag.org/content/2/10/e1600097 